\title{
APUNTES SOBRE ALGUNOS PROBLEMAS \\ DE LA INVESTIGACIÓN DEL ARTE PREHISPANICO \\ DE MESOAMÉRICA
}

Por Dúrdica Ségota Tomac

Las obras de arte presentan la sociedad de su tiempo, responden a sus necesidades y se integran en un mundo histórico-social determinado.

Adolfo Sánchez Vázquez 1

El punto inicial para el estudio del arte de una sociedad determinada en una época específica, implica el estudio de su formación económicosocial; es decir, del proceso social compelejo y unitario, y de las transformaciones que esta estructura ha sufrido en distintos periodos de su existencia. ${ }^{2}$

El análisis de un complejo cultural rebasa la tarea de un estudioso del arte; pero el fenómeno artístico en cuanto a sus determinantes sociales, y los elementos que lo constituyen (forma, contenido, función, articulación), solamente podxá ser comprendido a través de la amplia perspectiva que dicho enfoque nos proporciona.

Para una investigación sobre el arte llamado occidental hacer abstracción total o parcial de la formación económico-social, en la cual fue creada la obra de arte, no representa un problema tan grave como lo sería en el caso de una investigación sobre el arte no occidental, debido a distintos grados de conocimiento del proceso histórico.

Sin embargo, tampoco se llega a comprender cabalmente el arte occidental si se hace tal abstracción. Sería tal vez más fácil hacerlo en el caso de una investigación acerca del arte de nuestra época, del siglo $\mathrm{xx}$, pero este acto de abstracción sería en cierta forma inconsciente, ya que un historiador o un teórico del arte hoy dia tiene mayor posibilidad para comprender el arte de su época, puesto que tanto él como el creador de una obra de arte participan en mayor o menor grado, y a pesar de las diferencias en las vivencias individuales, en los mismos procesos sociales, económicos, políticos e ideológicos. Aunque no indague

1 Adolfo Sánchez Vázquez, 1975, vol. I, p. 327.

2 Para el concepto de "formación económico-social" vid. Emilio Sereni, 1976, pp. $55 \cdot 97$. 
a fondo y no actúe de manera científica, propiamente dicha, este teórico tendrá mayor posibilidad de acertar en sus juicios estéticos y apreciaciones artísticas. Pero no sucederá lo mismo si se aventura, por ejemplo, en un análisis del arte de la Alta o Baja Edad Media. El grado de "familiaridad" es obviamente distinto. E1 romántico y el gótico, des. pués de siglos de "olvido" y de la degradación de sus valores estéticos, volvieron a ser apreciados hasta el siglo xrx. El interés renace cuando la clase social que lo había reprimido, la burguesa, ya se sentía suficentemente segura de sí misma y consideraba inofensivo el contenido del arte del medievo; es decir, portador de la ideología feudal que combatía. A partir de ese momento se comienza a estudiar la "tenebrosa" Edad Media, su sociedad, pensamiento, arte, etcétera. $Y$ solamente a partir de los estudios del complejo cultural que integra el medievo, "recobra" valor su arte.

La dificultad aumenta acercándonos al arte no occidental, llamado con frecuencia "primitivo", pese a toda la ligereza y vaguedad que este término implica. La fase colonial del capitalismo tuvo razones muy concretas para ignorar intencionalmente los valores que encarna y representa este arte, ya que sus valores eran expresión de las sociedades, en cuanto a su modo de producción e ideología, que prefirió dominar en todos aspectos antes que comprenderlos. No es sino hasta mediados del siglo pasado, con el desarrollo de la ciencia antropológica, cuando despierta la inquietud para indagar más a fondo las características específicas de las culturas no occidentales, su estructura y transformación.

$\mathrm{Y}$ es precisamente por causa del colonialismo señalado, que con frecuencia se analiza el arte no occidental, incluyendo el de Mesoamérica, con base en criterios, cánones y gustos europeos. Creemos que no es la manera de llegar a entenderlo. Se Debería analizar la cultura en su totalidad para comprender los elementos que lo integran; tener conciencia que el arte no es sino una de tantas instituciones de una sociedad que lo determina y sobre la cual el arte a su vez actúa. Además, entendiéndolo de tal manera, abrimos una posibilidad de ampliar el concepto occidental de arte y enriquecer el gusto y la sensibilidad artística.

Para una empresa de tal magnitud desde luego lo ideal sería una investigación interdisciplinaria de investigadores del arte, historiadores, arqueólogos, antropólogos, ecólogos, lingüistas, etcétera. Este planteamiento puede parecer como un alejamiento del estudio del arte, o por 
lo menos una labor para el sociólogo del arte, pero es la única manera de comprenderlo.

De lo anterior se deduce que el arte como proceso y manifestación no es independiente y por ello expresamos la necesidad del estudio de la formación económico-social, pero es autónomo como proceso y manifestación; es derir, tiene su propio campo, lenguaje, desarrollo y leyes que lo diferencian y separan de las demás instituciones. ${ }^{3}$ Los aspectos relacionados con la: dependencia y la autonomía del arte son las dos etapas metodológicas más importantes para la investigación. En la primera se pretende hacer la sociología del arte, nutriéndose de los estudios que las demás ciencias sociales aportan a determinados temas; una segunda etapa sería propiamente el estudio de la historia del arte. Pero ninguna de las dos etapas puede bastarse a sí misma, sin tener necesidad de la otra; de lo contrario el problema del arte queda incomprendido, esta vez no intencionalmente sino por falta de una visión del conjunto.

Hay una mayor razón para plantear el problema de tal manera cuando nos encontramos ante un complejo cultural como el de Mesoamérica, que representa una civilización a la cual integran una serie de instituciones cuyas características en la gran mayoría de los casos difieren radicalmente de la civilización del Occidente. Y no solamente se distinguen estas características por el número y el grado de desarrollo, sino también por la manera como se interrelacionan. Así, por ejemplo, la dependencia y la autonomía del arte tienen características peculiares sin paralelo en el arte occidental. Pedro Carrasco dice al respecto que la civilización mexica:

... es un tipo de cultura caracterizado por un sistema de producción con cultivos intensivos y artesanías desarrolladas capaz de mantener una población numerosa en la que existía una división de trabajo que incluía la distinción entre la ciudad y el campo, entre un grupo de trabajadores dedicados principalmente a la producción de bienes materiales y otros dedicados a la distribución y el gobierno; una sociedad que podía producir refinamientos culturales como un sistema de mantener registros, si bien no fuera la escritura alfabética, un calendario sumamente elaborado, edificios monumentales, artes primorosas y una religión muy completa que demandaba participación de sacerdotes especializados.. 4

3 Para el concepto de "independencia" y "autonomia", vid. Adolfo Sánchez Vázquez, 1976, pp. $287-315$.

4 Pedro Carrasco, 1976, vol I, p. 168 
Aunque la descripción anterior se refiere específicamente a la cultura mexica, la mayoría de los conceptos e instituciones que menciona se pueden aplicar a la civilización mesoamericana en general. El arte se encuentra entre estos elementos, pero no de una manera aislada y, por lo tanto, lo podríamos entender solamente si comprendemos el conjunto.

Veamos algunos de estos problemas. La unidad cultural de Mesoamérica se ha tratado de explicar desde hace varias décadas en base a distintos criterios. Paul Kirchhof 5 aplica un criterio étnico; sin embargo, tal pauta se mostró inoperante en varios niveles, inclusive en los estudios del arte. ¿Cómo podríamos explicar la homogeneidad y la heterogeneidad del arte mesoamericano? Pensemos en las diferencias que existen entre las tierras altas de Guatemala (sur) y las tierras bajas (norte de Guatemala y península de Yucatán) en cuanto a las obras arquitectónicas. Ambas regiones pertenecen a la cultura maya $y$, sin embargo, pese a las similitudes que existen, las diferencias son tan grandes que han hecho pensar a Silvanus Morley ${ }^{6}$ que en el surgimiento de estas obras pertenecía a distintos horizontes culturales. Caso opuesto es la homogeneidad estilística en el Teotihuacan a pesar de la heterogeneidad étnica de su población.

Para responder satisfactoriamente a la pregunta acerca de la diversidad estilística necesitaríamos indagar más a fondo. Algunos estudiosos de la cultura prehispánica han planteado otro criterio, haciendo hincapié en los factores ecológicos y han logrado explicar algunas diferencias entre las áreas mesoamericanas con base en las condiciones del medio ambiente y su relación con el hombre. ${ }^{7}$ Han establecido, por ejemplo, los patrones de asentamiento correspondientes a tierras altas y tierras bajas de Mesoamérica, y algunas características relacionadas con los modos de producción. El factor geográfico, sin ser de ninguna manera el único factor determinante para una civilización, deja sentir su presencia en muchos aspectos y así también en el arte. Mencionaremos, por ejemplo, el tipo de materiales con los cuales se dispone en una región para la obra artística; los motivos que ofrece (la flora, la fauna). Además, no hay que olvidar que el hombre prehispánico se dedicaba principalmente a la agricultura y su contacto con la naturaleza era obviamente primordial para su existencia, así las formas religiosas expresadas en el arte no fueron solamente un resultado de las relaciones

5 Paul Kirchhoff, 1967.

6 Silvanus Morley, 1956.

7 Michael Logan y William Sanders, 1976, pp. 31 - 59 
sociales, sino también la consecuencia de la relación de los hombres con la naturaleza. Pero con este criterio se incurrió de nuevo en un error, el de buscar la respuesta a una problemática tan compleja como es una formación económico-social, a través de un solo factor: el ecológico.

Nos parece que solamente con el estudio de la sociedad en su totalidad, con sus diversas estructuras que se encuentran en una interacción y transformación constantes, existe la posibilidad de encontrar una respuesta. El modo de producción con sus fuerzas productivas y las relaciones sociales de producción es de un interés fundamental para el estudio de una sociedad y su arte, puesto que nos permite descubrir el grado de la diferenciación social, especialización del trabajo, importancia del comercio, etcétera; todas ellas elementos esenciales para entender el arte como trabajo. Una sociedad con división del trabajo muy diversificada y jerarquización social compleja posibilita y estimula la producción artística, en cuanto la cantidad de obras de arte y en cuanto la calidad de obras producidas. La jerarquización de los grupos sociales es una de las condiciones para la especialización del artista, y esto determina un mejor dominio de las técnicas y deja a la vez la posibilidad de una búsqueda de nuevas formas artísticas; aunque esta búsqueda dependerá más del factor ideológico. La misma jerarquización, así como la especialización juegan en la sociedad prehispánica papel importantísimo en su economía; tanto en Teotihuacan, la zona maya $\mathrm{u}$ otras áreas, ya que precisamente las piezas-muebles de arte que producen los artistas (¿o artesanos?) fueron uno de los principales objetos del comercio exterior. La especialización manufacturera, junto con el comercio, fue uno de los factores determinantes para la existencia de los grandes centros ceremoniales y urbanos, el crecimiento de la población no agrícola y el fortalecimiento de la economía de la ciudad, desde los inicios del horizonte Clásico hasta la Conquista. La organización social prehispánica propiciaba el trabajo artístico tanto por el sistema de encargo, como por la posibilidad propia del estrato dominante (la nobleza) de exigir al pueblo que una parte del tributo fuera pagado en forma de trabajo. El estudio de la infraestructura de la sociedad mesoamericana, y en especial del proceso del trabajo, estudiadas en distintos periodos $\mathrm{y}$ en distintas áreas, abre una posibilidad para responder a la pregunta acerca de la posición y función social del artista, y también al planteamiento de lo que pudo haber sido el arte para dicha sociedad. 
El complemento para la respuesta a tales preguntas deberíamos buscarlo en las características de la superestructura, ya que, como dice Gramsci: "Estructura y superestructura forman un bloque histórico donde el complejo discorde y contradictorio de la superestructura es el reflejo del conjunto de las relaciones sociales de producción... (entre ambas) existe siempre una reciprocidad, que es el proceso dialéctico real." 8

A su vez, las instituciones que integran la supraestructura, entre otras la política, la jurídica, la religiosa, la artística, etcétera, se encuentran en una estrecha interacción; por regla general tales procesos se dan bajo el sello de la ideología dominante. Esta interacción y reciprocidad entre las estructuras y entre diversas instituciones tiene como resultado una transformación social constante (aunque pueden existir, en determinados momentos de la historia, fuertes tendencias de man tener ciertos tipos de interacción de estos factores, con el fin de mantener el status quo de la situación social y política). La ideología dominante tiende a dar un sello de homogeneidad a toda estructura social, y de hecho su función principal es de cohesión social y de justificación del poder de quienes lo detentan.

El arte en cuanto a su dependencia tiene con los demás factores ideológicos una vinculación fuerte y pronunciada, directa, podríamos decir. Representa y manifiesta las relaciones que hemos mencionado arriba y las comunica a través de un lenguaje propio, artístico. Sin embargo, el arte nunca llega a subsumirse en la ideología, desde luego, ya que faltando su autonomía no podríamos ni siquiera hablar del arte como tal. Precisamente el grado de la dependencia y de la autonomía es el que varía mucho de una cultura a otra y de un periodo a otro.

En una sociedad como la prehispánica de Mesoamérica fue necesario un control ideológico directo y contundente, con el fin de garantizar la reproducción del sistema, o dicho con otras palabras, garantizar las relaciones sociales de producción. Nos parece que el arte muestra una mayor dependencia, con las demás instituciones, en las sociedades que se encuentran en el proceso de consolidación del poder político; manifiestan una mayor rigidez de formas y contenidos, alejándose muy poco de los cánones establecidos - como sucede en la escultura mexica en el siglo XIV y en la primera mitad del siglo xv.

Al contrario, el arte experimenta menor dependencia y mayor autonomia cuando existe cierta solidez y seguridad social y política y da cabida

8 Antonio Gramsci, 1969, p. 100. 
a rebuscamientos y un lenguaje artístico más rico-ejemplo de ello observamos en el arte maya del Clásico Tardío (600-900) -; inclusive, posibilita el surgimiento de estilos locales - un buen ejemplo es el arte de la región maya de Usumacinta (Yaxchilán, Piedras Negras, Bonampak) en el Clásico Tardío.

Es necesario mencionar aquí que el arte prehispánico que estudiamos hoy, en la gran mayoría de los casos, pertenece a las manifestaciones artísticas de un arte oficial, arte que representa la ideología del estrato alto, dominante, de la nobleza. Hoy conocemos mejor este arte que el arte de estratos bajos, por varias razones. Entre otras, mencionaremos que las ciudades prehispánicas fueron construidas mediante estructuras en forma de anillos concéntricos en cuyo núcleo se encontraba el centro religioso y las habitaciones de la nobleza, mientras el pueblo vivía en los anillos exteriores; lo que conocemos ahora a través de las excavaciones arqueológicas son los núcleos y muy raras veces la periferia. Además la nobleza, debido a la cantidad de la mano de obra de la que disponía (trabajo como tributo, obras de arte por encargos, etcétera), pudo realizar gran cantidad de obras monumentales por su tamaño y cantidad. El arte de pueblo es menos estudiado, menos excavaciones se han hecho en la zona donde habitaba el campesino, pero es posible hacer un análisis de este arte si el estudio de las antiguas piezas existentes se complementa con un estudio etnológico, ya que tanto las creencias populares como las formas de expresión artística tienden a sobrevivir largo tiempo entre la gente de pueblo, mientras la ideología y el arte oficial desaparecen junto con el poder que sustentaban y representaban. 9 No queremos decir con esto que en Mesoamérica existían paralelamente dos artes radicalmente distintos, pero sí que, inscribiendose éstas en un contexto de diferentes estratos sociales, obedecían a distinto tipo de relaciones (dependencia), así que sus formas y las transforciones que éstas sufrían variarían también (atonomía).

El estudio de los factores que hemos mencionado en las páginas ante. riores daría posiblemente una respuesta más precisa a las preguntas acerca de la homogeneidad y la heterogeneidad del arte mesoamericano, sobre el papel de artista en la sociedad, sobre la problemática del arte como tal y tal vez muchas otras.

E1 modo de producción jugaba en la sociedad prehispánica, como en cualquier otra sociedad, un papel determinante en la producción artística, pero éste tenía, como dijimos, un margen de independencia y de

Ibidem, pp. $61-85$. 
posibilidad de creación, lo que daría a este trabajo precisamente el carácter de artístico.

Una vez determinado en grado y tipo de autonemía de la que gozaba, entraremos en la segunda fase metodológica de nuestra investigación, o sea al estudio de la historia del arte propiamente dicha; a la investigación acerca de los estilos, cambios de las formas y de los contenidos, distintos géneros artísticos, tecnicas, semejanzas y diferencias iconográficas, etcétera. Necesitaríamos desglosar cada uno de estos elementos propios y autónomos del arte, ver su interacción y evolución, y podríamos para ello utilizar el método de análisis comparativo sincrónico y diacrónico, ${ }^{10}$ pero nosotros no nos extenderemos aquí acerca de esta problemática.

Febrero, 1977.

\section{BIBLIOGRAFIA}

Carrasco, Pedro. "La Sociedad Mexicana Antes de la Conquista". Historia general de México, Colegio de México. México, 1976, 3 vol.

Foncerrada, Marta de Molina "La Pintura Mural de Cacaxtla". XLII Congreso Internacional de Americanistas. París, 1976. Simposio Metodología en la Investigación del Arte Prehispánico. Inédito.

Gramsci, Antonio. La formación de los intelectuales. Grijalbo, México, 1967. Col. "7ọ", núm. 2.

KirchHoff, Paul. "Mesoamérica, sus limites geográficos, composición étnica y caracteres culturales", INAH. México, 1967. Suplemento de la revista Tlatoani, núm. 2

LogAn, Michael., H. Sanders, William T. "The Model". The Valley of Mexico, Studies in Pre-Hispanic Ecology and Society, Ed. Eric Wolf Univertsity of New Mexico Press. Alburquerque, 1976.

Morley, Silvanus G. La civilación Maya, FCE. México, 1956.

Sánchez VÁzquez, Adolfo. Estética y marxismo, Ed. Era. México, 1975 2 a ed 2 vol.

- "Là ideología y la neutralidad ideológica en las ciencias sociales." La filosofia y las ciencias sociales, Ed. Grijalbo. México, 1976. Col. Teoría y Praxis, núm. 24.

SERENI, Emilio. "La categoría de formación económico-social", en Luporini Cesare, et al. El concepto de formación económico-social, Siglo XXI México, 1976. Cuadernos de Pasado y Presente, núm. 39.

10 Ver acerca de este método el trabajo de Marta Foncerrada de Molina, 1976. 